\title{
Cytokeratin 20-positive hepatocellular carcinoma
}

\author{
D. Fanni, ${ }^{1}$ S. Nemolato, ${ }^{1}$ R. Ganga, ${ }^{2}$ G. Senes, ${ }^{1}$ C. Gerosa, ${ }^{1}$ P. Van Eyken, ${ }^{3}$ K. Geboes, ${ }^{3}$ \\ G. Faa
}

${ }^{1}$ Department of Pathology, University of Cagliari, Italy; 'Division of Internal Medicine, Casa di cura Lay, Cagliari, Italy; ${ }^{3}$ Department of Pathology, K.U. Leuven, Leuven, Belgium

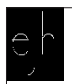

(C)2009 European Journal of Histochemistry

The differential diagnosis between hepatocellular carcinoma (HCC), cholangiocarcinoma (CC) and metastatic colorectal adenocarcinoma (MCA) may be difficult when only based on morphology. For this purpose immunohistochemical analyses are often required, utilizing antibodies directed against CK818, Hep-Par1, glypican 3, CK7, CK19, CK20. Here we report a case of a 65-year-old man who presented with a clinical picture of decompensated cirrhosis. Ultrasonography revealed two nodular areas in the right liver lobe. Liver needle biopsy revealed micro-macronodular cirrhosis associated with HCC with trabecular and pseudoglandular patterns. Immunohistochemically, tumour cells were diffusely positive for CK818 and also diffusely immunostained by glypican 3 and HepPar1. Interestingly, a diffuse and strong staining for CK20 was detected in the vast majority of tumor cells, particularly in the areas showing a pseudo-glandular pattern. No immunostaining for CK7 and CK19 was found in the tumor cells. The tumor behaved aggressively, with a rapid diffusion to the whole liver. The patient died from the disease few months after presentation. These findings underline that the interpretation of the expression of CK20 alone in the differential diagnosis among HCC, CC and MCA should be done with caution because a diffuse immunoreactivity for CK20 alone may not rule out the diagnosis of HCC.

Key words: hepatocellular carcinoma, cholangiocarcinoma, metastatic colorectal carcinomas, CK20.

Correspondence: Daniela Fanni,

Department of Pathology, University of Cagliari, Istituto di Anatomia Patologica, Ospedale San Giovanni di Dio, Via Ospedale n. 60, 09124 Cagliari (Italy).

Tel.: +39.070.6092370 - 6092372- 6092487.

Fax: +39.070.657882

E-mail: fandan73@yahoo.it

Paper accepted on September 29, 2009

European Journal of Histochemistry

2009; vol. 53 issue 4 (October-December): 269-274
The differential diagnosis between hepatocellular carcinoma (HCC), cholangiocarcinoma (CC) and metastatic colorectal adenocarcinoma (MCA) may be difficult when only based on morphology (Terracciano et al., 2003).

In fact, a subset of extrahepatic adenocarcinomas of different origin may show a solid "hepatoid" pattern virtually indistinguishable from HCC (Porcell et al., 2000). On the other hand, the undifferentiated form of HCC may mimic poorly differentiated tumors of different origin, while its tubular and adenoid variants may be indistinguishable from CC or from MCA.

In these cases, immunohistochemical analyses are often required (Stroescu et al., 2006).

The panel of antibodies utilized to solve this differential diagnosis includes: CK8-18 (Porcell et al., 2000) Hep-Parl (Leong et al., 1998) (Zimmerman et al., 2001), glypican 3 (GPC3) (Yamauchi et al., 2005) (Capurro et al., 2003), CK7 (Maeda et al., 1996) (Chu et al., 2000), CK20 (Faa G et al., 1998), CK19, CEA and Alpha-fetoprotein (Onofre et al., 2007) (Lau et al., 2002).

Immunoreactivity of tumour cells for CK8-18, Hep-Par 1 and GPC3 is considered suggestive of $\mathrm{HCC}$; a diffuse immunoreactivity for $\mathrm{CK} 7$ and CK19 is in favour of the diagnosis of CC; a diffuse positivity for CK20 and negativity for CK7 are normally associated with MCA.

Here we report a case of HCC with a peculiar immunohistochemical profile, characterized by the association of the typical immunoreactivity of $\mathrm{HCC}$ with a diffuse and strong positivity for CK20, generally considered typical of MCA. 


\section{Materials and Methods}

\section{Clinical history}

A 65-year-old man was referred to our hospital because of asthenia and jaundice. On clinical examination, a picture of decompensated cirrhosis was evident: edema of the lower extremities, ascites, palpable spleen. Laboratory tests showed an increase in serum levels of transaminases (3-4 times normal values), gammaglutamyltranspeptidase ( 3 times normal values), and bilirubin (total: $14.8 \mathrm{mg} / \mathrm{dL}$; conjugated: $9.1 \mathrm{mg} / \mathrm{dL}$ ). Viral markers for HBV and HCV were negative. The patient suffered from alcoholic cirrhosis, diagnosed at the age of 47. Esophago-gastroduodenoscopy revealed esophageal varices. Six months before admission, ultrasonography performed during a surveillance program detected two hyperechogenic space-occupying lesions in the right lobe of the liver, 3 and $2.4 \mathrm{~cm}$ in diameter respectively. Computed tomography performed three months later, showed multiple mildly hypodense nodules in the right liver lobe, with a hypervascular pattern suggestive of HCC. On admission, liver ultrasound scan showed a tremendous diffusion of the proliferating nodules throughout the whole liver, with the tendency to occupy the entire organ. Alphafetoprotein and carcinoembryonic antigen serum levels were in the normal range. In order to evaluate the irregular nodular areas, echo-guided needle liver biopsy was performed.

\section{Sample preparation}

The needle liver biopsy was formalin-fixed, paraffin-embedded and routinely processed. Immunohistochemical stainings were performed using antibodies against $\mathrm{CK} 8-18$ (clone $35 \beta \mathrm{H} 11$ and clone DC 10, Dako Denmark A/S, Glostrup, Denmark), CK20 (clone K520.8, Dako Denmark A/S, Glostrup, Denmark), CK7 (clone OV-TL 12/30, Dako Denmark A/S, Glostrup, Denmark), CK19 (clone RCK 108, Dako Denmark A/S, Glostrup, Denmark), Hep-Parl (clone OCHlE5, Dako Denmark A/S, Glostrup, Denmark) and GPC3 (clone 1G12, Biomosaic, Inc, Burlington, VT, USA).

Tissue sections were dewaxed, rehydrated through graded alcohols and pre-treated with heat-induced epitope retrieval in 0,01 $\mathrm{M}$ Citrate buffer pH 6.00 (GPC33, Hep-Par1, CK7, CK8 and CK18) or 0,1 M Tris Base/0,01 M EDTA pH
9.00 (CK19 and CK20) for immunohistochemical analyses. Slides were incubated for 30 minutes at room temperature with a 1:200 dilution of a polyclonal anti GPC3 primary antibody and with 1:50 dilutions of monoclonal antibodies directed against the following antigens: Hep-Parl, CK7, CK8, CK18, CK20. Staining procedures were performed by Dako REAL EnVision Detection System Peroxidase (Dako Denmark A/S, Glostrup, Denmark) following the manufacturer's instructions.

As a control group, we examined the expression of CK20 in 20 previously diagnosed HCC.

\section{Clinical follow-up}

Five months after liver biopsy, the patient developed hepatic encephalopathy and died.

\section{Results}

The histological examination of the liver biopsy showed two distinct patterns. Silver stain revealed a completely modified hepatic architecture, due to the presence of diffuse porto-central bridging fibrous septa, associated with regenerating hepatocytes arranged in two-cell-thick trabeculae. Portal tracts and bridging septa often contained a mild inflammatory infiltrate, with rare foci of interface hepatitis. Micro and macrovesicular steatosis was homogeneously distributed throughout the regenerating nodules. Mallory bodies were also detected in the cytoplasm of large hepatocytes with clear cytoplasm. Iron deposition was focally observed in hepatocytes and in Kupffer cells. In the deeper part of the bioptic core, with the interposition of a thin fibrous capsule, we observed the proliferation of neoplastic cells, similar in size and shape to hepatocytes, arranged in two architectural patterns: the trabecular one was characterized by 3-4 cell-tick trabeculae; the adenoid pattern showed smaller cells arranged around a central lumen (Figure 1). Mitotic figures were rare. Nuclear vacuoles and pseudoinclusions were frequently observed. On the basis of the morphological findings, the diagnosis of micro-macronodular cirrhosis with mild activity, compatible with alcoholic aetiology, complicated by well differentiated hepatocellular carcinoma was performed. At immunocytochemistry, the first panel of antibodies applied evidenced a diffuse 

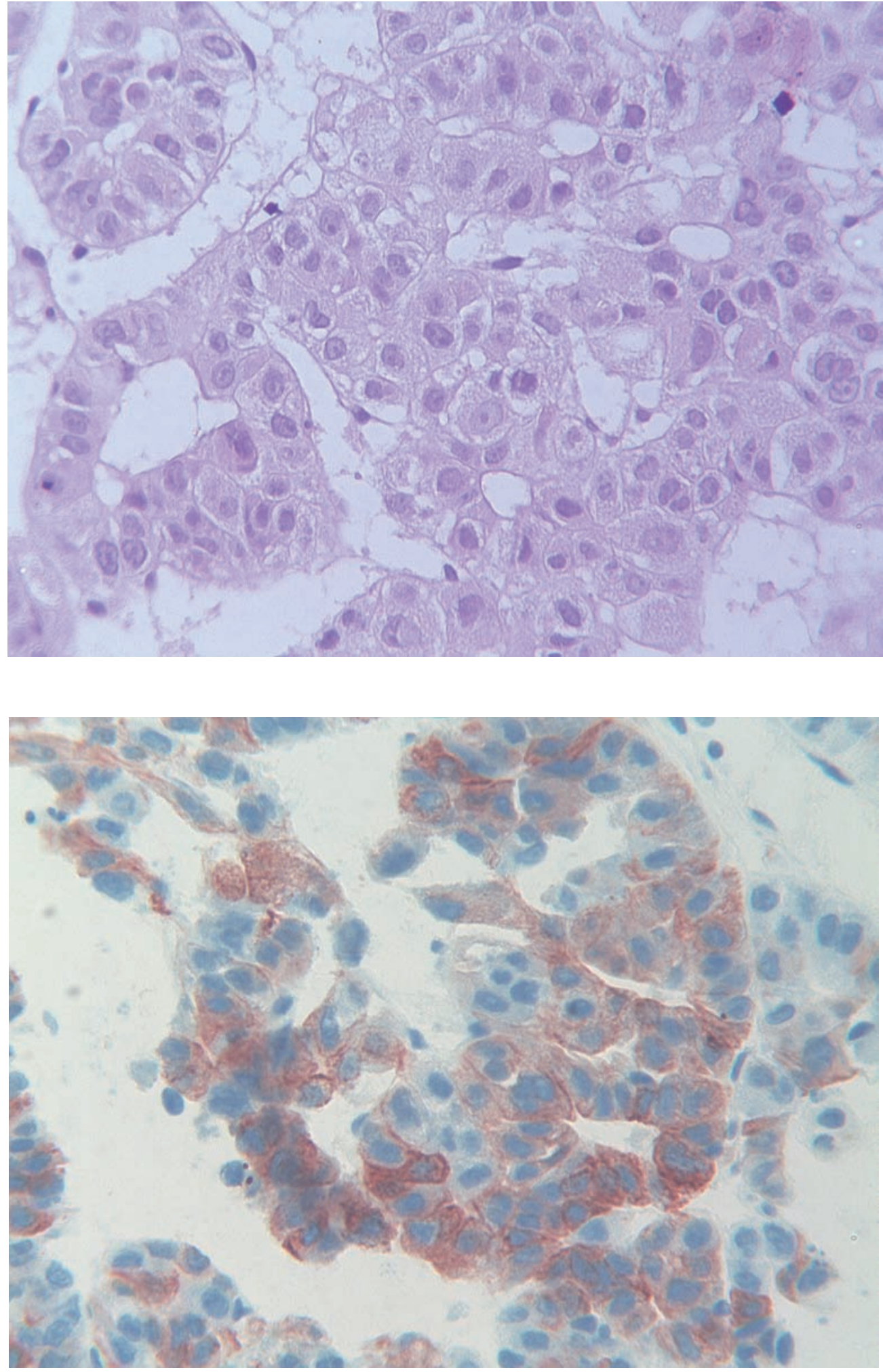

Figure 1. Hepatocellular carcinoma showing a mixed trabecular and adenoid pattern. H\&E.
Figure 2. Intense cytoplasmic immunoreactivity for CK20 of the majority of tumor cells. immunoreactivity of tumor cells for CK8 and $\mathrm{CK} 18$, and the absence of immunostaining for $\mathrm{CK}$ 7 and CK19. Due to the presence of tumor areas showing an adenoid pattern, with psuedoglandular arrangement of tumor cells, we also immunostained tumor cells for CK20. The result of the staining was straightforward: immunoreactivity for CK20 appeared diffuse in the vast majority of 
neoplastic cells. The percentage of CK20-positive cells ranged from about $50 \%$ in areas with trabecular features up to $90 \%$ in tumor zones showing an adenoid pattern (Figure 2). Given the discrepancy among immunohistochemical data obtained applying the first panel, we also tested immunoreactivity of tumor cells for Hep-Parl and glypican3. The typical granular cytoplasmic reactivity for Hep-Parl was found in the vast majority of tumor cells as well as in the surrounding liver. The majority of tumor cells were also immunostained by glypican 3, which was completely negative in the surrounding liver. In the control group, 19 out of 20 previously diagnosed HCCs did not show any immunoreactivity for CK20, the latter one evidenced a slight focal positivity in scattered tumor cells.

\section{Discussion}

Although clear criteria for the histological diagnosis of HCC have been established by the International Working Party (1995), the differential diagnosis of HCC vs CC and MCA may be not so easy, especially when scant material is available for histology (Zhu et al., 2001). The report of liver metastases from adenocarcinomas of extrahepatic origin showing hepatoid features, underlines the possibility of diagnostic errors when the diagnosis is only based on morphology (Porcell et al., 2000). A report from our group of a striking intratumoral variability in $\mathrm{HCC}$, related to morphology and to immunoreactivity of tumor cells, highlights the role of sampling variability as a possible cause of pitfalls in diagnosing HCC (Senes et al., 2007). Although poorly differentiated HCC may lose immunoreactivity for $\mathrm{CK} 8$ and $\mathrm{CK} 18$ (Van Eyken et al., 1988), HCC is usually $\mathrm{CK}^{+}$, $\mathrm{CK} 18^{+}, \mathrm{CK} 7^{-}, \mathrm{CK} 19^{-}, \mathrm{CK} 20^{-}$(Chu et al., 2002). In clinical practice, the use of CK7/CK20 immunostaining is considered a useful tool in distinguishing $\mathrm{HCC}\left(\mathrm{CK}^{+}\right.$in $10 \%$; $\mathrm{CK} 20^{+}$in $\left.7 \%\right)$ from periferal CC $\left(\mathrm{CK}^{+}\right.$in $96 \%$; $\mathrm{CK} 20^{+}$in $47 \%$ ) (Rullier et al., 2000), non periferal CC $\left(C K 7^{+}\right.$in $96 \%$; CK20+ in $82 \%$ ) (Rullier et al., 2000), colorectal carcinoma (CK7+ in 27\%; CK20+94\%) (Chu et al., 2002), pancreatic cancer (CK $7^{+} 94 \% ; C K 20^{+}$ $52 \%$ ) (Chu et al., 2002) and hepatoblastoma $\left(\mathrm{CK}^{+} 26 \%\right.$ ) (Chu et al., 2002) (Fiegel et al., 2004) (Table 1). In normal human tissues, CK20
Table 1. CK7/CK20 immunostaining.

\begin{tabular}{lcc}
\hline & CK 7 & CK 20 \\
\hline HCC & $10 \%$ & $7 \%$ \\
Periferal CC & $96 \%$ & $47 \%$ \\
Non periferal CC & $96 \%$ & $82 \%$ \\
Colorectal carcinoma & $27 \%$ & $94 \%$ \\
Pancreatic cancer & $94 \%$ & $52 \%$ \\
Hepatoblastoma & $26 \%$ & n.a. \\
\hline
\end{tabular}

immunoreactivity is restricted to gastric and intestinal epithelium (Botta et al., 2000), Merkel cells of the skin (Miettinen, 1995), and transitional epithelium (Southgate et al., 1999), whereas it is absent in the liver. In carcinomas, a diffuse immunoreactivity for $\mathrm{CK} 20$ is restricted to a few tumors: colon cancer (90\%), Merkel cell tumor $(86 \%)$, transitional cell carcinoma (68\%), gastric carcinoma $(56 \%)$, and pancreatic carcinoma $(56 \%)$ (Chu and Weiss, 2002).

Here we report a case of HCC showing an immunohistochemical pattern normally considered typical for a metastasis originating from gastrointestinal tract primaries (Moll, 1998): a diffuse and strong immunoreactivity of the vast majority of tumor cells for CK20. In previous studies CK20 expression has been reported in rare cases of $\mathrm{HCC}$, always restricted to scattered tumor cells, and with such a reactivity never creating diagnostic problems (Maeda et al., 1996). On the contrary, in our case, the simple application of the panel CK7/CK20 could have excluded the hepatocellular origin of the tumor, in favour of an hepatoid form of colorectal cancer (Terracciano et al., 2003). The reason for this atypical expression of $\mathrm{CK} 20$ in our case is unknown. Little information is available concerning the factors that regulate the expression of keratin genes in different cell types, in health and disease (Moll et al., 1982). A study from our group on CK20 expression in rat liver demonstrated a strong proliferation of $\mathrm{CK}_{2} \mathrm{O}^{+}$cells following an experimentally induced cholestasis (Faa et al., 1998), showing that keratin expression patterns do not necessarily reflect histogenesis, but may be influenced even by epigenetic factors.

From a practical point of view, the present case confirms previous reports on the complexity of making an unequivocal diagnosis of HCC. The possibility of negativity of small HCCs for HepPar 1 (Sugiki et al., 2004), the patchy expression 
of CK8-18 (Van Eyken P et al., 1988), the uneven distribution of GPC-3 (Yamauchi et al., 2005) (Capurro et al., 2003) suggest the possibility of sampling errors and recommend that caution should be taken in the interpretation of immunohistochemical data concerning HCC.

\section{Aknowledgements}

The authors want to thank Mrs. Laura di Pietro and Mr. Ignazio Ferru for secretarial assistance.

\section{References}

Botta MC, Ambu R, Liguori C, Van Eyken P, Pisanu A, Cabras A et al. CK20 expression in the gastrointestinal tract of the embryo and fetus. Pathologica 2000;93:649-4.

Capurro M, Wanless IR, Sherman M, Deboer G, Shi W, Miyoshi E et al. Glypican-3: a novel serum and histochemical marker for hepatocellular carcinoma. Gastroenterology 2003;125:89-97.

Chu PG, Wu E, Weiss LM. Cytokeratin 7 and Cytokeratin 20 expression in epithelial neoplasms: a survey of 435 cases. Mod Pathol 2000;13:962-72.

Chu PG, Weiss LM. Keratin expression in human tissues and neoplasms. Histopathology 2002;40:403-39.

Faa G, Van Eyken P, Roskams T, Miyazaki H, Serreli S, Ambu R et al. Expression of cytokeratin 20 in developing rat liver and experimental models of ductular and oval cell proliferation. J Hepatol $1998 ; 29: 628-33$

International Working Party Terminology of hepatocellular nodular lesions. Hepatology 1995; 22:983-93

Fiegel HC, Glüer S, Roth B, Rischewski J, von Schweinitz D, Ure B et al. Stem-like cells in human hepatoblastoma. J Histochem Cytochem. 2004;52:1495-501.

Lau SK, Prakash S, Geller SA, Alsabeth R. Comparative immunohistochemical profile of hepatocellular carcinoma, cholangiocarcinoma, and metastatic adenocarcinoma. Hum Pathol 2002;33:1175-81.

Leong AS, Sormunen RT, Tsui WM, Liew CT. Hep-Parl and selected antibodies in the immunohistological distinction of hepatocellular carcinoma from cholangiocarcinoma, combined tumours and metastatic carcinoma. Histopathology 1998;33:318-24.

Maeda T, Kajiyama K, Adachi E, Takenaka K, Sugimachi K, Tsuneyoshi M. The expression of cytokeratins 7, 19, and 20 in primary and metastatic carcinomas of the liver. Mod Pathol 1996;9:901-9.

Miettinen M. Keratin 20: immunohistochemical marker for gastrointestinal, urothelial and Merkel cell carcinomas. Mod Pathol 1995;8:384-8.
Moll R, Franke WW, Schiller DL, Geiger B, Krepler R. The catalog of human cytokeratins: patterns of expression in normal epithelia, tumors and cultured cells. Cell 1982;31:11-24.

Moll R. Cytokeratins as markers of differentiation in the diagnosis of epithelial tumors. Subcell Biochem 1998;31:205-62.

Onofre AS, Pomjanski N, Buckstegge B, Bocking A. Immunocytochemical diagnosis of hepatocellular carcinoma and identification of carcinomas of unknow primary metastatic to the liver on fine-needle aspiration cytologies. Cancer 2007; 111:25968.

Porcell AI, De Young BR, Proca DM, Frankel WL. Immunohistochemical analysis of hepatocellular and adenocarcinoma in the liver: MOC31 compares favorably with other putative markers. Mod Pathol 2000;13:773-8.

Rullier A, Le Bail B, Fawaz R, Blanc JF, Saric J, Bioulac-Sage P. Cytokeratin 7 and 20 expression in cholangiocarcinomas varies along the biliary tract but still differs from that in colorectal carcinoma metastasis. Am J Surg Pathol 2000;24:870-6.

Senes G, Fanni D, Cois A, Uccheddu A, Faa G. Intratumoral sampling variability in hepatocellular carcinoma: a case report. World J Gastroenterol 2007;29:4019-21.

Southgate J, Harnden P, Trejdosiewicz LK. Cytokeratin expression patterns in normal and malignant urothelium: a review of the biological and diagnostic implications. Histol Histopathol 1999;14:657-64

Stroescu C, Herlea V, Dragnea A, Popescu I. The diagnostic value of cytokeratins and carcinoembryonic antigen immunostaining in differentiating hepatocellular carcinomas from intrahepatic cholangiocarcinomas. J Gastrointestin Liver Dis 2006;15:9-14.

Sugiki T, Yamamoto M, Aruga A, Takasaki K, Nakano M. Immunohistological evaluation of single small hapatocellular carcinoma with negative staining of monoclonal antibody Hepatocyte Paraffin-1. J Surg Oncol 2004;88:104-7.

Terracciano LM, Glatz K, Mhawech $\mathrm{P}$, Vasei M, Lehmann FS, Vecchione $\mathrm{R}$ et al. Hepatoid adenocarcinoma with liver metastasis mimicking hepatocellular carcinoma: an immunohistochemicaland molecular study of eight cases. AM J Surg Pathol 2003;27:130212.

Van Eyken P, Sciot R., Paterson A., Callea F, Kew MC, Desmet VJ. Cytokeratin expression in hepatocellular carcinoma: an immunohistochemical study. Hum Pathol 1988;19:562-8.

Yamauchi N, Watanabe A, Hishinuma M, Ohashi K, Midorikawa Y, Morishita $Y$ et al. The glypican 3 oncofetal protein is a promising diagnostic marker for hepatocellular carcinoma. Mod Pathol 2005;18:1591-8.

Zhu ZW, Friess $H$, Wang $L$, Abou-Shady M, Zimmermann A, Lander $A D$ et al. Enhanced glypican-3 expression differentiates the majority of hepatocellular carcinomas from benign hepatic disorders. Gut 2001;48:558-64.

Zimmerman RL, Burke MA, Young NA, Solomides CC and Bibbo M. Diagnostic value of hepatocyte paraffin 1 to discriminate hepatocellular carcinoma from metastatic carcinoma in fine-needle aspiration biopsies of the liver. Cancer 2001:93:288-91. 
D. Fanni et al. 